\title{
Desempenho e morfologia intestinal de frangos de corte alimentados com rações contendo aditivos alternativos a antimicrobianos
}

Aryana Duckur NUNES ${ }^{1}$

Andréia Cristina Nakashima

VAZ $^{1}$

Leonila Ester RASPANTINI ${ }^{2}$

Evanildo Moreira da SILVA ${ }^{1}$

Ricardo de ALBUQUERQUE ${ }^{1}$

Correspondência para:

Aryana Duckur Nunes, Avenida Duque de Caxias Norte, 225, Campus USP, Depto VNP, 13635-9000. Pirassununga-SP aryananunes@usp.br

Recebido para publicação: 09/01/2008 Aprovado para publicação: 24/09/2009

\author{
1 - Departamento de Nutrição e Produção Animal da Faculdade de Medicina \\ Veterinária e Zootecnia da Universidade de São Paulo, Pirassununga-SP \\ 2 - Centro de Pesquisa em Toxicologia Veterinária do Departamento de Patologia \\ da Faculdade de Medicina Veterinária e Zootecnia da Universidade de São \\ Paulo, Pirassununga-SP
}

\section{Resumo}

Este estudo avaliou o efeito de um prebiótico e de um probiótico sobre o desempenho e morfologia intestinal de frangos de corte, atuando como aditivos alternativos a antimicrobianos. Foram utilizados 960 pintos de corte, criados sobre cama reutilizada. O delineamento era inteiramente casualizado, com 4 tratamentos: Antibiótico (Avilamicina); Prebiótico (MOS); Probiótico (pool bacteriano); Controle (sem aditivo), sendo 8 repetições/tratamento. Considerando-se o período total de criação, os aditivos alternativos testados pioraram o GP em relação ao antibiótico não demonstrando efeito sobre o ganho de peso (GP) e consumo de ração (CR). Por sua vez, a conversão alimentar (CA) dos tratamentos com aditivos alternativos foi similar à do antibiótico, entretanto, não diferiu do controle. Não foi possível observar efeito benéfico dos aditivos alternativos testados sobre a morfologia intestinal de frangos de corte.
Palavras-chave: Alimentação. Antibiótico. Prebiótico. Probiótico. Promotores de crescimento.

\section{Introdução}

Frente à preocupação da saúde pública com o uso antimicrobianos promotores de crescimento na produção animal, principalmente relacionada à suposta indução de resistência cruzada de bactérias patógenas para humanos, intensificou-se a pesquisa de estratégias alternativas aos antimicrobianos, como é o caso de prebióticos e probióticos. ${ }^{1}$

Estudos têm demonstrado que tais aditivos promovem a modulação benéfica da microbiota intestinal, com efeito trófico sobre a mucosa intestinal, além de estímulos imunomoduladores. Segundo Santos et al. ${ }^{2}$, o resultado do uso destes aditivos alternativos é a melhor digestão e absorção de nutrientes e, consequentemente, um melhor desempenho animal sem aumentar significativamente os custos de produção.

Prebióticos foram definidos por Gibson e Roberfroid ${ }^{3}$ como ingredientes nutricionais não digeríveis na porção proximal do trato gastrintestinal, que beneficiam o animal por estimular seletivamente o crescimento de um limitado grupo de bactérias no intestino. Os prebióticos mais estudados são os oligossacarídeos, principalmente os frutoligossacarídeos (FOS), glucoligossacarídeos (GOS) e mananoligossacarídeos (MOS).

Foi relatado por Collet ${ }^{4}$ que o MOS liga-se às fímbrias de bactérias patogênicas, promovendo a eliminação destes patógenos do trato intestinal. O resultado é uma colonização favorável por microrganismos benéficos, como Bifidobacterium spp, Lactobacillus spp e Eubacterium spp. ${ }^{5}$

Probiótico foi definido por Fuller ${ }^{6}$ como sendo um suplemento alimentar constituído de microrganismos vivos, que no organismo animal atua de forma benéfica melhorando o equilíbrio da microbiota intestinal. Alguns estudos descrevem os seguintes mecanismos de ação destes aditivos: 
competição por sítios de ligação e nutrientes; produção de substâncias antibacterianas; aumento da atividade enzimática nos microvilos intestinais; supressão da produção de amônia; neutralização de enterotoxinas; efeito trófico sobre a mucosa intestinal; estímulo ao sistema imune. , $7,8^{-1}$

Savage, Zakrzewska e Andreasen $\mathrm{Jr}^{9}$, Macari e Maiorka ${ }^{10}$ e Loddi ${ }^{11}$ demonstraram o efeito trófico da suplementação com prebióticos e probióticos sobre a mucosa intestinal. Furlan, Macari e Luquetti ${ }^{12}$ relatam que tal efeito ocorre com a indução do desenvolvimento da mucosa intestinal, ou seja, estímulo do processo mitótico na região cripta-vilo. Consequentemente, aumenta o número de células e o tamanho do vilo.

Diante do exposto, o presente ensaio teve como objetivo comparar o desempenho e a morfologia intestinal de frangos de corte alimentados com rações contendo antimicrobiano, prebiótico e probiótico.

\section{Material e Método}

O experimento foi conduzido em março e abril de 2007, na Faculdade de Medicina Veterinária e Zootecnia da Universidade de São Paulo, Campus Pirassununga.

As dietas eram isonutritivas, à base de milho e farelo de soja, cuja formulação obedecia aos níveis nutricionais rotineiramente empregados na criação comercial de frangos de corte. A dieta da fase inicial (01-21 dias) possuía $2950 \mathrm{kcal} /$ $\mathrm{kg}$ de energia metabolizável (EM), 22,5\% de proteína bruta (PB), 0,35\% de metionina, $0,71 \%$ de metionina + cistina, $0,95 \%$ de cálcio e $0,45 \%$ de fósforo disponível. A dieta de crescimento (22-35 dias) possuía $3100 \mathrm{kcal} /$ $\mathrm{kg}$ de EM, 20,0\% de PB, 0,32\% de metionina, $0,65 \%$ de metionina + cistina, $0,95 \%$ de cálcio e $0,35 \%$ de fósforo disponível. A dieta da fase final (35-42 dias) possuía $3150 \mathrm{kcal} / \mathrm{kg}$ de EM, 18,0\% de PB, 0,30\% de metionina, $0,60 \%$ de metionina + cistina, $0,90 \%$ de cálcio e $0,30 \%$ de fósforo disponível. Os níveis dos demais nutrientes estavam de acordo com aqueles rotineiramente empregados na criação comercial de frangos de corte. A ração foi fornecida ad libitum durante todo período de criação.

Um total de 960 pintos de um dia, machos e da linhagem AgRoss 308 foram criados até 42 dias de idade sobre cama reutilizada. As aves foram pesadas e distribuídas de forma inteiramente casualizada em 4 diferentes tratamentos: Dieta Basal (DB) com Antibiótico; DB com Prebiótico; DB com Probiótico; Controle (sem aditivo). Havia oito repetições (boxes) por tratamento de 30 aves cada.

O antibiótico era avilamicina (10 ppm). O prebiótico era o MOS, derivado da parede celular de Saccharomyces cerevisae, na dose $1 \mathrm{~kg} /$ ton de ração para a fase inicial e $0,5 \mathrm{~kg} /$ ton de ração para as fases de crescimento e final. O probiótico era um pool bacteriano composto por: Lactobacillus acidophilus, Streptococcus faecium e Bifidobacterium bifidum (3,5 x $\left.10^{8} \mathrm{UFC} / \mathrm{g}\right)$, na dose $2 \mathrm{~kg} / \mathrm{ton}$ de ração. Não foi adicionado à ração nenhum anticoccidiano ou qualquer outro aditivo que não os em estudo.

As aves e a sobra de ração foram pesadas aos 21, 35 e 42 dias de idade para a determinação das seguintes variáveis: ganho de peso médio (GP), consumo médio de ração (CR), e conversão alimentar (CA).

Aos 42 dias de idade foram coletados fragmentos do duodeno, jejuno e íleo de 8 animais por tratamento, sendo uma ave de cada repetição, para a análise da morfologia intestinal através da microscopia de luz. Após o abate por deslocamento cervical, os fragmentos foram coletados e lavados em solução salina, sendo fixados em solução de Bouin por 24 horas. Posteriormente foram desidratados com álcool, diafanizados, impregnados em xilol e incluídos em parafina. Os cortes histológicos foram corados com Hematoxilina-eosina de Harris para mensuração da altura dos vilos, profundidade das criptas e contagem das células caliciformes. Foi preparada uma lâmina por segmento intestinal de cada animal. Em cada lâmina havia três cortes 
semi-seriados com seis micrômetros de espessura.

Para a morfometria foram mensurados vinte vilos e vinte criptas por lâmina, com aumento de 12,5 vezes. A contagem do total das células caliciformes de cinco vilos por lâmina foi realizada com um contador digital, utilizando o aumento de 40 vezes. A partir dos valores encontrados, obteve-se a média por segmento intestinal de cada animal para altura de vilo, profundidade de cripta e número de células caliciformes por vilo.

Os resultados foram analisados através do software Statistical Analisys System ${ }^{13}$. Os dados foram submetidos à análise de variância e, quando observada diferença significativa entre os tratamentos $(\mathrm{P}<0,05)$, as suas médias foram comparadas através do teste de Tukey, a um nível de significância de 5\%.

\section{Resultados e Discussão}

Os resultados referentes ao desempenho estão apresentados na tabela 1. Para o intervalo de 1-21 dias os aditivos alternativos mostraram GP similar ao antibiótico, entretanto não diferiram do controle. Para o intervalo de 1-35 dias o probiótico permaneceu com GP similar ao antibiótico, mas não diferiu do controle. Já o prebiótico deixou de alcançar o desempenho do antibiótico. Por fim, no período total de criação ambos aditivos alternativos não atingiram mais o mesmo GP do antibiótico, que foi superior a todos os demais tratamentos.

Os resultados obtidos no presente trabalho discordam dos encontrados por Santin et al. ${ }^{14}$ para os períodos de 1-21 dias e 1-42 dias. Estes autores observaram maior peso vivo para as aves que receberam prebiótico ou probiótico, comparado com as que receberam ração sem aditivos e também observaram maior GP com o uso de prebióticos em relação ao controle e, atribuíram esse melhor desempenho ao efeito trófico do produto na mucosa intestinal.

Concordando com os resultados aqui obtidos até os 21 dias de idade, Flemming et al. ${ }^{15}$ verificaram que $0,05 \%$ MOS e $0,05 \%$ de parede celular de $S$. cerevisae tiveram efeito similar a $0,005 \%$ do antibiótico Olaquindox. Zulkifli $^{16}$ observaram, na fase inicial de frangos de corte, um similar GP entre aves tratadas com probiótico e antibiótico e a superioridade de ambos os tratamentos em relação ao controle. Entretanto, muitos trabalhos relatam a ausência de efeito dos aditivos alternativos sobre o GP. É o caso de Loddi ${ }^{11}$ testando um pool bacteriano (Bacillus subtilis; L. jobnsonii; L. reuteri) e de Dionízio, Bertechini e Kato ${ }^{17}$ avaliando diferentes fontes de prebióticos (FOS, manose, lactose, sacarose) no período total de criação.

Tabela 1 - Ganho de peso médio (GP), consumo de ração médio (CR), e conversão alimentar (CA) nos intervalos: $1-21 ; 1-35$ e 1-42 dias, sob os diferentes tratamentos - Pirassununga, 2007

\begin{tabular}{|c|c|c|c|c|c|c|}
\hline \multirow[t]{2}{*}{ Parâmetros } & \multicolumn{4}{|c|}{ Tratamentos } & \multirow[b]{2}{*}{$\mathrm{P}$} & \multirow[b]{2}{*}{ CV\% } \\
\hline & Antibiótico & Prebiótico & Probiótico & Controle & & \\
\hline \multicolumn{7}{|l|}{ 01-21 dias } \\
\hline GP $(\mathrm{g})$ & $842,50 \mathrm{a}$ & 824,63 ab & 835,25 ab & 808,38 b & 0,0265 & 2,99 \\
\hline CR (g) & 1204,13 & 1212,25 & 1205,25 & 1193,88 & 0,6531 & 2,35 \\
\hline $\mathrm{CA}(\mathrm{g} / \mathrm{g})$ & 1,43 & 1,47 & 1,44 & 1,48 & 0,2727 & 3,91 \\
\hline \multicolumn{7}{|l|}{$01-35$ dias } \\
\hline GP $(\mathrm{g})$ & $2206,00 \mathrm{a}$ & $2147,63 \mathbf{b}$ & $2161,86 \mathbf{a b}$ & $2118,00 \mathrm{~b}$ & 0,0002 & 2,13 \\
\hline CR (g) & 3548,13 & 3540,50 & 3530,57 & 3515,38 & 0,8026 & 1,90 \\
\hline $\mathrm{CA}(\mathrm{g} / \mathrm{g})$ & $1,61 \mathbf{a}$ & $1,65 \mathbf{a b}$ & $1,63 \mathbf{a b}$ & $1,66 \mathbf{b}$ & 0,0356 & 2,41 \\
\hline \multicolumn{7}{|l|}{$01-42$ dias } \\
\hline GP $(\mathrm{g})$ & $2942,00 \mathbf{a}$ & $2832,86 \mathbf{b}$ & $2840,33 \mathbf{b}$ & $2848,50 \mathrm{~b}$ & 0,0021 & 2,44 \\
\hline CR (g) & 5121,50 & 5030,43 & 5033,67 & 5064,25 & 0,2722 & 1,97 \\
\hline $\mathrm{CA}(\mathrm{g} / \mathrm{g})$ & $1,74 \mathbf{a}$ & $1,77 \mathbf{a b}$ & $1,77 \mathbf{a b}$ & $1,78 \mathbf{b}$ & 0,0167 & 1,61 \\
\hline
\end{tabular}


Quanto ao CR, nos três intervalos estudados não foi possível observar diferença significativa com o uso de qualquer aditivo. Também Maiorka et al. ${ }^{18}$, não observaram efeito de avilamicina, FOS, MOS ou probiótico (L. acidophillus, L. casei, S. lacteis, S. Faecium, B. bifidum e Aspergillus oryzae) no CR e no GP de frangos de 1-40 dias de idade.

Outros experimentos demonstraram a influência de prebióticos e probióticos sobre o consumo de frangos de corte. É o caso de Vesna et al. ${ }^{19}$, que verificaram o menor CR com o uso do MOS comparado ao grupo controle, durante os 42 dias de criação. Da mesma forma, Corrêa et al. ${ }^{20}$ observaram menor $\mathrm{CR}$ no grupo suplementado com probiótico em relação ao controle, no período de 1-21 dias de idade.

Para o intervalo de 1-21 dias não foi demonstrado efeito dos aditivos alternativos sobre a CA. Entretanto, estes alcançaram CA similar àquela obtida com antibiótico, apesar de não terem diferido do controle, no intervalo de 1-35 dias e no período total de criação. Maiorka et al. ${ }^{18}$ discordam destes resultados ao relatarem melhor $\mathrm{CA}$ do prebiótico, probiótico e simbiótico comparados ao controle no período de 1-40 dias. No estudo de Silva ${ }^{21}$ a inclusão de prebiótico na ração pré-inicial (1-7 dias) resultou em maior GP e melhor CA nas aves, criadas sob alta temperatura, ao final de 42 dias de idade. Tal resultado é atribuído à possível redução do $\mathrm{pH}$ intestinal que deprime o crescimento de microrganismos patogênicos. Zulkiflii ${ }^{16}$, Corrêa ${ }^{20}$ et al. e Pelicano et al. ${ }^{22}$ relataram melhor CA no grupo que recebeu probiótico no período de 1-21 dias. Outros ensaios descrevem a ausência de efeito de prebióticos e probióticos sobre a CA de frangos de corte..$^{23,24}$

Portanto, pode-se mostrar que práticas de manejo e condições sanitárias adequadas, como as empregadas neste experimento, justificam a ausência de efeitos expressivos dos aditivos alternativos. Com relação à diversidade de resultados encontrados na literatura, podem ser listados vários fatores envolvidos, entre eles: estresse e situação sanitária do galpão, microrganismos que compõem o probiótico, diferenças de estrutura química e propriedades físico-químicas dos prebióticos, composição dos ingredientes da dieta e dosagens dos aditivos. ${ }^{25,26}$

Os resultados referentes à morfologia intestinal são apresentados na tabela 2. Não foi possível observar efeito positivo dos aditivos alternativos sobre quaisquer parâmetros morfológicos avaliados, nos três segmentos intestinais. Isso porque o efeito trófico esperado seria expresso através do aumento da altura dos vilos, da profundidade de criptas e do número de células caliciformes por vilo.

Autores relatam que a alta

Tabela 2 - Morfologia Intestinal: Altura de vilo (Alt. vilo); Profundidade de cripta (Prof. cripta); Número de células calicifomes por vilo ( $N^{\circ}$ cél. cal./vilo) - Pirassununga, 2007

\begin{tabular}{|c|c|c|c|c|c|c|}
\hline \multirow[t]{2}{*}{ Parâmetros } & \multicolumn{4}{|c|}{ Tratamentos } & \multirow[b]{2}{*}{$\mathrm{P}$} & \multirow[b]{2}{*}{$\mathrm{CV} \%$} \\
\hline & Antibiótico & Prebiótico & Probiótico & Controle & & \\
\hline \multicolumn{7}{|c|}{ Alt. vilo $(\mu \mathrm{m})$} \\
\hline Duodeno & $1810,52 \mathbf{a b}$ & $1837,67 \mathbf{a b}$ & $1564,28 \mathbf{b}$ & $2140,92 \mathbf{a}$ & 0,0011 & 16,68 \\
\hline Jejuno & $980,84 \mathbf{a b}$ & $952,94 \mathbf{b}$ & $1079,48 \mathbf{a b}$ & $1133,76 \mathbf{a}$ & 0,0177 & 13,11 \\
\hline Íleo & 567,22 & 549,90 & 614,23 & 587,40 & 0,7823 & 21,62 \\
\hline \multicolumn{7}{|c|}{ Prof. cripta $(\mu \mathrm{m})$} \\
\hline Duodeno & 238,25 & 251,25 & 246,04 & 241,86 & 0,8763 & 13,01 \\
\hline Jejuno & $159,60 \mathbf{b}$ & $168,90 \mathbf{b}$ & $166,94 \mathbf{b}$ & 207,21 a & 0,0077 & 18,34 \\
\hline Îleo & $126,24 \mathbf{a b}$ & $108,07 \mathbf{b}$ & $105,18 \mathbf{b}$ & $131,06 \mathbf{a}$ & 0,0058 & 15,23 \\
\hline \multicolumn{7}{|c|}{$\mathrm{N}^{\circ}$ cél. cal./vilo } \\
\hline Duodeno & $283 \mathbf{a b}$ & 214 b & $314 \mathbf{a}$ & 242 ab & 0,0114 & 25,43 \\
\hline Jejuno & 141 & 180 & 200 & 220 & 0,0992 & 35,79 \\
\hline Îleo & 105 & 111 & 119 & 105 & 0,8133 & 27,57 \\
\hline
\end{tabular}


profundidade de cripta indica alta atividade proliferativa celular. Isso ocorre não só devido ao efeito trófico de um ingrediente da dieta, mas também devido a alguma injúria de mucosa por processo inflamatório e, visa renovar perdas na altura dos vilos. ${ }^{12}$

Savage, Zakrzewska e Andreasen Jr. ao suplementar perus com MOS e Loddi ${ }^{11}$ suplementando frangos com MOS e acidificante orgânico, não só observaram o aumento da altura do vilo bem como o aumento do número de células caliciformes. Da mesma forma, Yang et al. ${ }^{24}$ obtiveram o aumento na altura de vilos de frangos de corte suplementados com $0,1 \%$ e $0,2 \%$ de MOS e com bacitracina-zinco. Estes autores também observaram, durante a fase inicial de criação, a maior digestibilidade no intestino delgado de frangos suplementados com MOS.

Iji, Saki e Tivey ${ }^{27}$ observaram o maior comprimento dos vilos do jejuno de frangos suplementados com alto nível de MOS $(0,5 \%)$, mas não observaram efeito de diferentes níveis de suplementação de MOS $(0,1 \% ; 0,3 \% ; 0,5 \%)$ sobre a profundidade de cripta e largura do vilo no jejuno e íleo. Já foram demonstradas as vantagens do uso de probióticos sobre a integridade do trato gastrintestinal. ${ }^{28}$ Estes adicionaram um cultivo misto de células viáveis (L. acidophilus; $E$. faecium; B. bifidum) na dieta de suínos e, observaram maior comprimento dos vilos e profundidade de criptas comparado ao grupo suplementado com L. acidophilus inativado e ao grupo controle.

Awad et al. ${ }^{29}$, estudando o efeito do probiótico Eubacterium sp. em frangos que receberam ração contaminada com a micotoxina deoxivalenol, observaram que o probiótico foi capaz de reduzir as alterações morfológicas intestinais causadas pela toxina. No entanto, outros ensaios concordam com os resultados aqui apresentados, ou seja, não demonstraram efeito positivo dos aditivos alternativos sobre a morfologia intestinal. Entre eles, Pelicano ${ }^{30}$ ao testar probiótico (Bacillus subtilis e pool bacteriano) e MOS em frangos de corte aos 42 dias de idade.

Como observado para desempenho, os resultados referentes à morfologia intestinal podem não ter evidenciado os efeitos dos aditivos alternativos em função de inúmeros fatores interferentes já citados. Ainda, é possível que o emprego de cama reutilizada no presente trabalho não tenha representado um desafio suficiente para evidenciar o efeito dos aditivos.

\section{Conclusões}

O emprego de aditivos possibilitou ganho de peso similar ao grupo antibiótico, principalmente na fase inicial, apesar de não ter mantido tal desempenho até o fim da criação. Além disso, demonstraram capacidade de atingir conversão alimentar similar àquela obtida com o uso de antimicrobianos, e também não acarretaram efeito benéfico sobre a morfologia intestinal. O emprego de cama reutilizada parece não ter representado um desafio suficiente para evidenciar o efeito dos aditivos, assim, em condições experimentais, a busca por situações mais próximas da realidade é um fator importante a ser considerado nos ensaios. Desta maneira, faz-se necessária a continuidade de estudos que analisem os efeitos de aditivos alternativos a antimicrobianos.

\section{Agradecimentos}

À FAPESP (Fundação de Amparo a Pesquisa do Estado de São Paulo) pela bolsa de mestrado concedida e pelo apoio financeiro ao projeto de pesquisa (Procs. $n^{\circ}:$ 06/53354-0; 06/53349-7); à empresa Alltech, Imeve e Elanco pelo fornecimento dos aditivos testados; à empresa Tortuga pelo fornecimento do suplemento vitamínico-mineral; ao Laboratório de Morfofisiologia Molecular e Desenvolvimento pertencente ao Departamento de Ciências Básicas da Faculdade de Zootecnia e Engenharia de Alimentos, Universidade de São Paulo, por disponibilizar os equipamentos necessários à morfometria intestinal. 


\section{Performance and intestinal morphology of broilers of cut fed with rations containing alternative additive instead of antimicrobials}

\section{Abstract}

This study evaluated the effect of a prebiotic (MOS) and of a probiotic (bacterial poo), acting as alternative additives instead of antibiotics, on the performance and on the intestinal morphology of broilers. In this experiment, 960 chicks were used on litter previously used. The birds were randomly assigned to four different treatments: Antibiotic; Prebiotic; Probiotic; and the control treatment, with eight repetitions for each treatment. For the whole breeding period (42 days) the alternative additives did not show any effect on the weight gain and feed intake. The feed conversion in the alternative additives groups was similar to that of the antibiotic group, however, it was not significantly different from that of the control group. It was not possible to observe any beneficial effect of the alternative additives, used in this essay, on the intestinal morphology of broilers.

\section{Referências}

1 PATTERSON, J. A.; BURKHOLDER, K. M Application of prebiotics and probiotics in poultry production. Poultry Science, v. 82, n. 4, p. 627-631, 2003.

2 SANTOS, E. C.; TEIXEIRA, F. S.; FREITAS, R. T. F. de RODRIGUES, P. B.; DIAS, A. S.; MURGAS, L. D. S. Uso de aditivos promotores de crescimento sobre o desempenho e características de carcaça e bactérias totais do intestino de frangos de corte. Ciência Agrotécnica, v. 29, n. 1, p. 223-231, 2005.

3 GIBSON, G. R.; ROBERFROID, M. B. Dietary modulation of the human colonic microbiota: introducing the concept of prebiotics. Journal of Nutrition, v. 125, n. 6, p. 1401-1412, 1995.

4 COLLET, S. Nutrição, imunidade e produtividade. In: RONDA LATINO AMERICANA DA ALLTECH: O FUTURO DA ALIMENTAÇÃO, 10., 2000, Campinas: Anais... Campinas: Alltech, 2000. p. 20-30.

5 OYFO, B. A.; DELOACH, J. R.; CORRIER, D. E.; NORMAN, J. O.; ZIPRIN, R. L.; MOLLENHAUER, C. Prevention of Salmonella thyfimurium colonization of broilers with D-mannose. Poultry Science, v. 68, n 10, p. $1357-1360,1989$

6 FULLER, R. Probiotic in man and animals. Journal of Applied Bacteriology, v. 66, n. 5, p. 365-378, 1989.

7 EWING, W. N.; COLE, D. J. A. The living gut: An introduction to microorganisms in nutrition, $\mathrm{N}$. Ireland: Context, 1994. 220 p.

8 JIN, L. Z. Probiotic in poultry: modes of action. World's Poultry Science Journal, v. 53, p. 351-368, 1997.

9 SAVAGE, T. F.; ZAKRZEWSKA, E. I.; ANDREASEN
$J R, J . R$. The effects of feeding diets to poults on performance and the morphology of the small intestine. Poultry Science, v. 76, p. 139, 1997. Supplement 1.

10 MACARI, M.; MAIORKA, A. Função gastrointestinal e seu impacto no rendimento avícola. In: CONFERÊNCIA APINCO, 2000, Campinas: Anais... Campinas: FACTA, 2000, v. 2, p. 455-457.

11 LODDI, M. M. Probióticos, prebióticos e acidificantes orgânicos em dietas para frangos de corte. 2003. 52 f. Tese (Doutorado em Zootecnia) - Faculdade de Ciências Agrárias e Veterinárias, Universidade Estadual Paulista "Júlio de Mesquita Filho", Jaboticabal, 2003.

12 FURLAN, R. L.; MACARI, M.; LUQUETTI, B. C. Como avaliar os efeitos do uso de prebióticos, probióticos e flora de exclusão competitiva. In SIMPÓSIO TÉCNICO DE INCUBAÇÃO, MATRIZES DE CORTE E NUTRIÇÃO. 5., 2004, Balneário Camboriú, Santa Catarina: Anais... 2004. p. 6-28.

13 STATISTICAL ANALISYS SYSTEM. SAS Institute Incorporation. SAS User's guide: statistics. 8. ed. Canada: SAS, 2001.

14 SANTIN, E.; MAIORKA, A.; MACARI, M.; GRECCO, M.; SANCHEZ, J. C.; OKADA T. M.; MYASAKA, A. M. Performance and intestinal mucosa development of broiler chickens fed diets containing Saccharomyces cerevisae cell wall. Journal Applied Poultry Research, v. 10 , p. $236-244,2001$

15 FLEMMING J. S.; FREITAS J. R. S.; FONTOURA P.; MONTANHINI NETO R.; ARRUDA J. S. Use of mannanoligosaccharides in broiler feeding. Brazilian Journal of Poultry Science, v. 6, n. 3, p. 159-161, 2004

16 ZULKIFLI, I. Growth performance and immune response of two commercial broiler strains fed diets containing Lactobacillus cultures and oxytetracycline 
under heat stress conditions. British Poultry Science, v. 41, p. 593-597, 2000.

17 DIONÍZIO, M. A.; BERTECHINI A. G.; KATO R. K. Prebiótico como promotores de crescimento para frangos de corte-desempenho e rendimento de carcaça. Ciência e Agrotecnologia, v. 26, p. 1580-1587, 2002. Edição Especial.

18 MAIORKA, A.; SANTIN, E.; SUGETA, S. M. ALMEIDA, J. G.; MACARI, M. Utilization of prebiotics, probiotics or symbiotics in broiler chicken diets. Revista Brasileira de Ciência Avícola, v. 3, n. 1, p. 75-82, 2001.

19 VESNA, T.; LAZAREVIC, M.; SINOVEC, Z.; TOKIC, A. The influence of different feed aditives to performances and immune response in broiler chicken. Acta Veterinária, v. 57, n. 2-3, p. 217-229, 2007.

20 CORRÊA, G. S. S.; GOMES, A. V. C.; CORRÊA, A. B.; SALLES, A. S.; MATTOS, E. S. Efeitos de antibiótico e probióticos sobre desempenho e rendimento de carcaça de frangos de corte. Arquivo Brasileiro de Medicina Veterinária e Zootecnia, v. 55, n. 4, p. 467473, 2003.

21 SILVA, V. K. Extrato de levedura (Saccharomyces cerevisiae) e prebiótico na dieta pré-inicial para frangos de corte criados em diferentes temperaturas, 2006 169 f. Dissertação (Mestrado em Zootecnia) - Faculdade de Ciências Agrárias e Veterinárias, Universidade Estadual Paulista "Júlio de Mesquita Filho", Jaboticabal, 2006.

22 PELICANO, E. R. L.; SOUZA, P. A.; SOUZA, H. B. A.; LEONEL, F. R.; ZEOLA, N. M. B. L.; BOIAGO, M $M$. Productive traits of broiler chickens fed diets containing differents growth promoters. Brasilian Journal of Poultry Science, v. 6, n. 3, p. 177-182, 2004.

23 GUSILS, C. Alimentación probiótica para pollos. In: CONGRESSO LATINO AMERICANO DE AVICULTURA, 38., 2001, Guatemala: Anais... Guatemala, 2001, v. 31, p. 625 .
24 YANG, Y.; IJI, P. A.; KOCHER, A.; MIKKELSEN, L. L.; CHOCT, M. Effects of mannanoligosaccharide on growth performance, the development of gut microflora, and gut function of broiler chickens raised on new litter. Journal Applied Poultry Research, v. 16, p. 280 288, 2007.

25 SUNVOLD, G. D.; HUSSEIN, H. S. In vitro fermentation of cellulose, beet pulp, and citrus pectin using fecal inoculum from cats, dogs, horses, humans, and pigs and ruminal fluid from cattle. Journal of Animal Science, v. 73, n. 12, p. 3639-3648, 1995.

26 SILVA, L. P.; NORNBERG J. L. Prebióticos na nutrição de não-ruminantes. Ciência Rural, v. 33, n. 5 , p. 983-990, 2003.

27 IJI, P. A.; SAKI, A. A.; TIVEY, D. R. Intestinal structure and function of broiler chickens on diets supplemented with a mannan oligosaccharide. Journal of the Science of Food and Agriculture, v. 81, n. 12, p. 1181-1192, 2001.

28 RODRIGUES, M. A. M.; SILVA, D. A. D. O.; TAKETOMI, E. A.; HERNANDEZ-BLAZQUEZ, F. J. IgA production, coliforms analysis and intestinal mucosa morphology of piglets that received probiotics with viable or inactivated cells. Pesquisa Veterinária Brasileira, v. 27, n. 6, p. 241-245, 2007.

29 AWAD, W. A.; BOÌHM, J.; RAZZAZI-FAZELI, E.; GHAREEB, K.; ZENTEK, J. Effect of addition of a probiotic microorganism to broiler diets contaminated with deoxynivalenol on performance and histological alterations of intestinal villi of broiler chickens. Poultry Science, v. 85, n. 6, p. 974-979, 2006.

30 PELICANO, E. R. L. Desempenho, qualidade de carne e desenvolvimento da mucosa intestinal de frangos produzidos com probióticos e prebióticos, 2006. 117 f. Tese (Doutorado em Zootecnia) - Faculdade de Ciências Agrárias e Veterinárias, Universidade Estadual Paulista "Júlio de Mesquita Filho", Jaboticabal, 2006. 